\title{
From the Editor: Final Words
}

\author{
Jing Jian Xiao
}

Published online: 3 November 2011

(C) Springer Science+Business Media, LLC 2011

After serving as the editor for Journal of Family Economic Issues since 2001, I will step down by the end of 2011. The new editor will be Elizabeth Dolan at the University of New Hampshire. I believe she will be an excellent editor and bring more successes for JFEI in her term. For the past 11 years, I enjoyed working with the authors, reviewers, editorial board members, associate editors, guest editors, and production editors in Springer. I am gladly seeing that JFEI is growing from a smaller size journal that used to publish about 12 papers per year to now a journal with a larger size publishing over 40 papers per year. The authorship and readership have also been expanding to many other countries besides its traditional American bases. Since August 2008, we started to use the online editorial management system that increased greatly the efficiency and accuracy of manuscript management and effectively facilitated communications between editors, reviewers and authors. I would like to thank the University of Rhode Island for providing a supportive environment for me as the editor in the past years. I also thank production editors in Springer, Jennifer Hadley, Sharon Panulla, Priya Sambandam and Latha Kalyanaraman, for providing guidance and assistance promptly and ably when needed.

In my term as the editor, I encouraged submissions of original empirical, conceptual, and review papers on important family economic issues from diverse academic fields and from diverse regions around the world. More importantly, I encouraged original papers written by interdisciplinary teams. I asked authors to discuss how the family economic issues focused in their papers are related

J. J. Xiao $(\bowtie)$

University of Rhode Island, Transition Center, Kingston, RI 02881, USA

e-mail: xiao@uri.edu to family well-being. I let authors beware that the readers of this journal are from diverse disciplines and asked the authors to make their writing accessible to this diverse readership. In addition, I also asked authors of papers using a specific country data not only to convey unique information about that country but also discuss its contributions to the general, family economic literature. I hope JFEI will continue its tradition of being an interdisciplinary and international forum for researchers who are interested in important family economic issues worldwide.

\section{Helpful Associate Editors}

Because submissions increased greatly in the last couple of years, we started to use a system of associate editors since 2009. I thank Richard K. Caputo (welfare policy), Laura DeHann (work and family), John Grable (consumer finance), George W. Haynes (family business), Manouchehr Mokhtari (health), and José Alberto Molina (family economics) for serving as associate editors and utilizing their expertise in their specialized areas to help build up this emerging, interdisciplinary field that focuses on important family economic issues.

\section{Helpful Guest Editors for Special Issues}

In 2011, we published two special issues. Guest editors' contributions are greatly appreciated. One special issue is on health, economics and family role published in June 2011. Manouchehr Mokhtari served as the guest editor. The other special issue is on family finance published in this issue (December 2011). Karen Holden served as the guest editor. She invited papers that were originally presented at 
research forums on family finance held at the Center for Financial Security at the University of Wisconsin for the special issue. After the rigorous peer review process, three papers were accepted and included in this issue, which are written by Jeffrey Dew, Benjamin Levinger and his coauthors, and J. Michael Collins. Other papers in this issue are submitted to the regular issues and accepted after conventional peer review process handled by the editor and associated editors.

\section{Outstanding Reviewers}

Outstanding reviewers are defined as those who always provide thorough, constructive suggestions for the authors and considerate recommendations for the editors. They are always willing to help and complete their reviews on or before deadlines. Among 316 reviewers who served from August 2008 to October 2011, I would like to acknowledge following people as outstanding reviewers who helped with 19-10 reviews each in the past 3 years: Zhuo Chen, Clinton G. Gudmunson, Gregory Ponthiere, Scott Hall, Jeffrey Dew, Deanna Sharpe, Jinhee Kim, Manouchehr Mokhtari, Laura Dehaan, Marta Elliott, and Yi Cai.

\section{Reviewers from January 2011 to October 2011}

As the editor, I greatly appreciate assistance from editorial board members and ad hoc reviewers for their constructive suggestions and recommendations on manuscripts submitted to Journal of Family and Economics Issues. Their efforts contribute to the high quality of this journal. Acknowledgments of contributions of reviewers in previous years can be found in the January issue of each year. The following is a list of reviewers including editorial board members who reviewed manuscripts from January 2011 to October 2011:

Douglas Abbott
Richard Akresh
Elaine Anderson
Nan Marie Astone
Jay Bae
Bill Bailey
Burt Barnow
Jean W. Bauer
Andrea H. Beller
Lisa Benson
Alexandra Bernasek
Ann Berry
Ruth Berry
Ivan Beutler
Vibha Bhargava
Marcia Bok
Emilia Del Bono
Sylvia Brandt
Sonya Britt
Anne Burgess
Julio Cáceres
Yi Cai
Wendy Campione
Honggao Cao
Andrew Carswell
Kuo-Liang Chang
Yunhee Chang
Swarn Chatterjee
Anoshua Chaudhuri
Zhuo Chen
Andre Christie-Mizell
Brett Coffman

Douglas Abbott

Richard Akresh

Elaine Anderson

Nan Marie Astone

Jay Bae

Bill Bailey

Burt Barnow

Jean W. Bauer

Andrea H. Beller

Alexandra Bernasek

Ann Berry

Vibha Bhargava

Sylvia Brandt

Sonya Britt

Yi Cai

Honggao Cao

Andrew Carswell

Kuo-Liang Chang

Yunhee Chang

Swarn Chatterjee

Anoshua Chaudhuri

Andre Christie-Mizell

Brett Coffman
J. Michael Collins

Zeynep Copur

Sam Cupples

Melissa Curran

Sharon Danes

Simon Davies

Laura Dehaan

Enilda Delgado

Sharon DeVaney

Jeffrey Dew

Jaime L. Dice

Elizabeth Dolan

Mark Edwards

Marta Elliott

John Ermisch

Sarah Beth Estes

Rudy Fenwick

Patti J. Fisher

Jacki Fitzpatrick

Angela Fontes

Nicole Forry

Benjamin P. Foster

Jiarong $\mathrm{Fu}$

John Gilliam

Robin Goldberg-Glen

John Grable

Irina Grafova

Tal Gross

Kejian $\mathrm{Gu}$

Clinton G. Gudmunson

Craig Gundersen

Scott Hall

\author{
Chang Keun Han \\ Sherman Hanna \\ Celia Hayhoe \\ Aaron Hegde \\ Jeffrey Hill \\ Victor Hiller \\ Jeanne Hilton \\ Jr-Tsung Huang \\ Vanessa Hunn \\ Eun Jin Hwang \\ Nancy Jianakoplos \\ So-Hyun Joo \\ Jinhee Kim \\ John Knowles \\ Andreas Kuhn \\ Christine Lai \\ Douglas Lamdin \\ Sun-A Lee \\ Yoon Lee \\ Kuang-Ta Lo \\ Jean Lown \\ Shelly Lundberg \\ Maurice MacDonald \\ Peter Martin \\ Jariah Masud \\ Teresa Mauldin \\ David Maume \\ Manouchehr Mokhtari \\ Victor Montuenga \\ Eva Mork \\ Taryn Morrissey \\ Jason Murasko
}


Barbara Newman

Barbara O'Neill

Laura Pagani

Lance Palmer

Eric Park

Rochelle Parks-Yancy

Silvia Pasqua

Allison Pearson

Daphne E. Pedersen

Stephen Pimpare

Gregory Ponthiere

Joanne Pratt

Michael A. Quinn

Clifford A. Robb

Susan Roxburgh

Joyashree Roy
Robert Scott

Almudena Sevilla-Sanz

Deanna Sharpe

Margaret Sherraden

Mark Showalter

Sharron Singleton

Hyrum Smith

Seohee Son

Maria Stanfors

Alex Stewart

Susan Stites-Doe

Andrew K. G. Tan

Chuanyi Tang

Karla Teixeira

Eileen Trzcinski

Anne Winkler
Nancy Wong

Jiayun Wu

Xiaolin Xie

Ruoh-Nan Yan

Rui Yao

Fariba Yazdkhasti

Jung Sung Yeo

Kaili Yieh

Tansel Yilmazer

Wen You

Selamah Abdullah Yusof

Wei Zhang

Xiaoyong Zheng

David Zimmer 